\title{
Limb Deformity Treatment and Diagnosis in Freeman-Burian syndrome
}

\author{
Mikaela I Poling ${ }^{1}$ and Craig R Dufresne ${ }^{1,2}$ \\ ${ }^{1}$ Craig R Dufresne, MD, PC \\ ${ }^{2}$ Virginia Commonwealth University
}

February 2, 2022

Correspondence: Mikaela I Poling, 8501 Arlington BLVD, Ste 420, Fairfax, VA 22031, USA; Tel. +1 304-460-9038; Fax +1 703-207-2002; E-mail: research@duplastics.com

Author Contributions: Both authors contributed equally.

Acknowledgments: We thank CM Poling, M Pocket, W Cloud, and ES Tu. This manuscript is dedicated to the memory of Calvin Yang, formerly of the 2nd Battalion, 27th Infantry Regiment "Wolfhounds" of the US Army, who lost his life to complications of posttraumatic stress disorder several years after serving.

Conflict of Interest: The authors have no financial or other competing interests to disclose.

Funding: This work was unfunded.

Word Count: 842 (Body)

KEYWORDS

Freeman-Burian syndrome; Freeman-Sheldon syndrome; malignant hyperthermia; craniocarpotarsal dystrophy; whistling face syndrome; distal arthrogryposis type 2A; case reports; rare diseases; craniofacial abnormalities

We read with interest the article, "Holistic rehabilitation of a rare case of distal arthrogryposis: Freeman Sheldon syndrome," by Drs Sreeja, Sahoo, Barman, and Baral.[1] It is wonderful to see this syndrome discussed. Unfortunately, there were several unclear or inaccurate points, and recent publications were omitted, suggesting an incomplete literature search. As Freeman-Sheldon syndrome, now Freeman-Burian syndrome (FBS),[2] is exquisitely rare, many who believe they have encountered it in clinical practice are eager to publish their experience, despite the perils.

The authors present FBS as a variant of distal arthrogryposis,[1] but FBS is a unique condition.[3] Though similar appearing to some other conditions, especially distal arthrogryposes, FBS is genetically unique and has a unique clinical course.[3] Two studies have provided evidence that certain craniofacial findings are pathognomonic for FBS, [4-5] and a meta-analysis found distal arthrogryposes are not required for diagnosis. [4] Though many continue to use the classification, FBS can no longer be cogently classed as a distal arthrogryposis syndrome in the face of such evidence, and the most reasonable classification seems to be as a complex congenital myopathic craniofacial syndrome.[3]

The authors next speak of, "skeletal deformities", "skeletal anomalies", "skeletal features", and "skeletal abnormalities". [1] In the syndrome, problems involving the skeletal system are secondary effects of the primary myopathic process of fibrose tissue replacement of normal muscle fibers.[6] This fibrose tissue acts as 
constricting bands, the way collagen behaves in severe burns.[6] This is correlated with in vitro molecular myophysiology observations showing problems with the metabolic process for contraction and extreme muscle stiffness that reduces muscular work and power.[6] Misunderstanding of etiology in FBS has led to inappropriate treatment plans, especially surgeries, and has resulted in tragic, lifelong impairments.[4,6-7] As such, it is exceedingly rare for the types of operative hand and foot therapies described in this article to be helpful in FBS.

The authors describe FBS as an, "autosomal dominant trait and in rare cases as autosomal recessive and x-linked recessive".[1] It is believed that inherited cases either have a parent with clinical evidence of FBS or rarely are germline mosaicisms.[4-5,8] All inherited cases are believed to be autosomal dominant. Overall, most cases are not inherited (sporadic).[4-5] Moreover, prenatal ultrasound is not considered diagnostic.[6] In general, prenatal diagnosis is not considered feasible.[6] For women with FBS, testing polar bodies during in vitro fertilization is the best way to prevent FBS.[6]

Regarding the cardinal clinical findings in the syndrome, the authors describe common findings, some of which are included in the diagnostic criteria, but most are not.[1,4-5] The authors do not delineate the diagnostic criteria (microstomia, pursed lips, deep nasolabial folds, and $\mathrm{H}$ or $\mathrm{V}$-shaped chin defect and two major arthrogryposes - typically, camptodactyly with ulnar deviation and equinovarus).[1,4-5] Arriving at a correct diagnosis is paramount in FBS, as patient outcomes depend on it. [9] Similar-appearing conditions (i.e., distal arthrogryposes) react far more favourably than FBS to surgery.[1] In FBS, surgery to address foot deformities often has poor outcomes, and even more successful surgeries, such as craniofacial surgery, may require multiple revisions to overcome fibrose constricting band development.[6] The diagnostic clinical criteria is also strongly correlated with the presence of $M Y H 3$ mutations. [6]

The authors paradoxically suggest windmill vane deformity and ulnar deviation are separate findings,[1] but they are synonyms. The authors also speak of kyphosis, which is somewhat rare in FBS, but they do not mention scoliosis, which is common.[1,4] Spina bifida oculta is not part of FBS, and while pterygium colli occurs in FBS, it is a required finding in Sheldon-Hall syndrome.[1,4-5]

The authors state there is an association of malignant hyperthermia (MH) with FBS and urge caution.[1] Some patients with FBS do, indeed, develop hyperpyrexia during general anesthesia, but these hyperpyrexia events, which may include tachycardia and increased muscle rigidity, respond to ibuprofen and also occur where a malignant hyperthermia protocol was followed and in stressful, non-operative stress situations.[10] There is no evidence that MH is associated with FBS, though FBS anesthesia practice guidelines still suggest following an $\mathrm{MH}$ protocol.[10]

The patient's description does not include any of the diagnostically required craniofacial findings, and while photographs are provided, the resolution is insufficient.[1,4-5] As FBS has an estimated false-positive rate of $30-60 \%,[4]$ the absence of evidence that the patient met the criteria for FBS raises serious doubt concerning the patient's diagnosis. Without objective evidence for the patient's FBS diagnosis, the purpose of the case report is lost.

We applaud the authors' encouraging, hopeful, and optimistic tone and message that is lacking in so many articles.[1] We feel it is critical to express a realistically optimistic outlook for these patients. Expressing an optimistic perspective can encourage colleagues and patients' families, possibly improving patient outcomes on many levels.

Ten English-language case reports have been published between 2020-2022 purportedly describing FBS that contained similar, preventable errors.[1,11-19] Not conducting a thorough literature search and omitting recent articles was the common denominator among the articles.[20] In trying to address the shortcomings of each, we have responded to nine, with four letters already published.[20-23] This article illustrates the potential perils of describing a rare condition despite the best intentions.

\section{References}

1. Sreeja KS, Sahoo J, Barman A, Baral D. Holistic rehabilitation of a rare case of distal arthrogryposis: 
Freeman Sheldon syndrome. International Journal of Scientific Research. 2021;10(5). Available at: https: //www. worldwidejournals. com/international-journal-of-scientific-research(IJSR)/fileview/holistic-rehabilitation-of-a-rare-case-of-distal-arthrogryposisfreeman-sheldon-syndrome_May_2021_6121064717_ 8726505.pdf

2. Poling MI, Dufresne CR. Revisiting the many names of Freeman-Sheldon syndrome. J Craniofac Surg. 2018;29(8):2176-2178. doi: 10.1097/SCS.0000000000004802

3. Poling MI, Dufresne CR. Head first, not feet first: Freeman-Sheldon syndrome as primarily a craniofacial condition. Cleft Palate-Craniofac J. 2018;55(5):787-788. doi: 10.1177/1055665617753482

4. Poling MI, Dufresne CR, Chamberlain RL. Findings, Phenotypes, Diagnostic Accuracy, and Treatment in Freeman-Burian Syndrome. J Craniofac Surg. 2020;31:1063-1069. doi: 10.1097/SCS.0000000000006299

5. Stevenson DA, Carey JC, Palumbos J, Rutherford A, Dolcourt J, Bamshad MJ. Clinical characteristics and natural history of Freeman-Sheldon syndrome. Pediatrics. 2006;117:754-762. doi: 10.1542/peds.2005-1219

6. Poling MI, Dufresne CR, Chamberlain RL. Freeman-Burian syndrome. Orphanet J Rare Dis. 2019;14:14. doi: 10.1186/s13023-018-0984-2

7. Poling MI, Dufresne CR, McCormick RJ. Identification and Recent Approaches for Evaluation and Management of Rehabilitation Concerns for Patients with Freeman-Burian Syndrome: Principles for Global Treatment. J Ped Genet. 2020;09(03):158-163. doi: 10.1055/s-0040-1710339

8. Hague J, Delon I, Brugger K, Martin H, Abbs S, Park SM. Molecularly proven mosaicism in phenotypically normal parent of a girl with Freeman-Sheldon Syndrome caused by a pathogenic MYH3 mutation. Am J Med Genet A. 2016;170(6):1608-1612. doi: 10.1002/ajmg.a.37631

9. Poling MI, Dufresne CR, Portillo AL. Identification and recent approaches for evaluation, operative counseling, and management in patients with Freeman-Burian syndrome: principles for global treatment. J Craniofac Surg. 2019;30(8):2502-2508. doi: 10.1097/SCS.0000000000005968

10. Poling MI, Dufresne CR. Freeman-Burian syndrome. Anästh Intensivmed. 2019;60(1):S8-S17. doi: 10.19224/ai2019.S008

11. Kamal G, Shah SB, Gupta A. Anesthesia Challenges in the Management of Freeman-Sheldon Syndrome: Report of Two Cases and Literature Review. AANA J. 2020;88(1):35-38. PMID: 32008616.

12. Park J, Kang SW, Choi WA, Lee Y, Cho HE. Precise Pulmonary Function Evaluation and Management of a Patient With Freeman-Sheldon Syndrome Associated With Recurrent Pneumonia and Chronic Respiratory Insufficiency. Ann Rehabil Med. 2020;44(2):165-170. doi: 10.5535/arm.2020.44.2.165

13. Wróblewska-Seniuk K, Jarząbek-Bielecka G, Kędzia W. Freeman-Sheldon syndrome - a course of the disease from birth to adulthood. Clin Exp Obstet Gynecol. 2020;47(6): 978-982. doi: 10.31083/j.ceog.2020.06.5430

14. Sato Boku A, Sento Y, Hasegawa T, Tsutsumi K, Kamimura Y, So M, Kako E, Sobue K. Anesthetic management of a patient with Freeman-Sheldon syndrome undergoing oral surgery: a case report. Clin Case Rep. 2021;9(6):e04358. Published 2021 Jun 9. doi: 10.1002/ccr3.4358

15. Kiliçbay F, Küçük Kurtulgan H, Sidar Duman Y, Tunç G. A Case Report of Freeman-Sheldon Syndrome with Gastrointestinal Dysmotility in a Premature Newborn Delivered Due to Polyhydramnios. Turkiye Klinikleri J Case Rep. 2021;29(4):230-3. doi: 10.5336/caserep.2021-83838.

16. Wu TM, Chin LS. Treatment results of teratologic arthrogryposis in a case of Freeman-Sheldon syndrome: A 25-year follow-up. Formos J Surg. 2021;54:66-9. doi: 10.4103/fjs.fjs_79_20

17. Sehrawat S, Sural S, Sugumar PA, Khan S, Kar S, Jeyaraman M. Freeman-Sheldon Syndrome with Stiff Knee Gait - A Case Report. Journal of Orthopaedic Case Reports 2021 November;11(11):64-68. doi: 10.13107/jocr.2021.v11.i11.2518

18. Fayed M, Giska MA, Shievitz RC, Attali A, Younger J. Emergent Cesarean Delivery in a Patient With Freeman-Sheldon Syndrome Complicated by Preeclampsia, Acute Pulmonary Embolism, and Pulmonary Edema: A Case Report. Cureus. 2021;13(12):e20802. doi: 10.7759/cureus.20802

19. Bowman S, Noble G, Rahmani B, Mets M, Ralay Ranaivo H, Castelluccio V. A case of blepharophimosis: Freeman Sheldon syndrome [published online ahead of print, 2021 Oct 19]. Ophthalmic Genet. 
2021;1-4. doi: 10.1080/13816810.2021.1989603

20. Poling MI, Dufresne CR. Unsafe Care and Misunderstanding Diagnosis in Freeman-Burian syndrome: Problems in Writing Case Reports Involving Rare Conditions and Strategies for Improvement. Version: 3. Authorea [Preprint]. January 26, 2022. doi: 10.22541/au.164303994.43963430/v3

21. Poling MI, Dufresne CR. Letter. AANA J. 2020;88(5):54. Available at:

22. Poling MI, Dufresne CR. Letter: Precise Pulmonary Function Evaluation and Management of a Patient With Freeman-Sheldon Syndrome Associated With Recurrent Pneumonia and Chronic Respiratory Insufficiency. Ann Rehabil Med. 2020;44(5):409-410. doi: 10.5535/arm.20110

23. Poling MI, Dufresne CR. Accuracy of Facts About Freeman-Sheldon syndrome. Clin Exp Obstet Gynecol. 2021;48(5):997-998. doi: 10.31083/j.ceog4805160 